\title{
Identifikasi Potensi dan Masalah dalam Revitalisasi Kawasan Sungai Kalimas di Surabaya Utara
}

\author{
Inggar Rayi Arbani dan Hertiari Idajati \\ Departemen Perencanaan Wilayah dan Kota, Fakultas Teknik Sipil dan Perencanaan, Institut \\ Teknologi Sepuluh Nopember (ITS) \\ e-mail: hertiari_idajati@urplan.its.ac.id
}

\begin{abstract}
Abstrak-Pemerintah Kota Surabaya merencanakan untuk merevitalisasi Kawasan Sungai Kalimas sejak tahun 2006 yang memiliki 9 titik revitalisasi secara keseluruhan. Namun, sejak tahun 2010, pemerintah Kota Surabaya memfokuskan revitalisasi di Surabaya Utara yang terbagi menjadi 3 titik revitalisasi, yaitu Kawasan Pelabuhan Kalimas, Kawasan Jembatan Petekan, dan Kawasan Jembatan Merah. Kondisi 3 titik revitalisasi yang belum adanya perubahan yang signifikan maka dibutuhkan kajian mengenai potensi dan masalah masing-masing titik sebagai upaya untuk mengefektifkan proses revitalisai. Artikel ini merupakan bagian dari penelitian perumusan strategi revitalisasi pada Kawasan Sungai Kalimas di Surabaya Utara. Pengambilan data pada penelitian ini diperoleh melalui in-depth interview kepada stakeholder yang telah ditentukan sebelumnya serta studi literatur pad dokumen-dokumen perencanaan terkait kondisi eksisting kawasan. Teknik analisis yang digunakan dalam penelitian ini yaitu Content Analysis. Berdasarkan hasil penelitian diketahui bahwa potensi pada 3 titik revitalisasi ini yaitu kawasan ini masih memiliki peninggalan bersejarah berupa bangunan cagar budaya yang memiliki nilai historis tinggi. Kemudian, masalah pada kawasan ini yaitu adanya ketidakserasian pendapat antara pemerintah dan masyarakat, dan juga pemerintah daerah dengan pemerintah kota terkait penetapan status cagar budaya pada suatu bangunan.
\end{abstract}

Kata Kunci-Content Analysis, Kawasan Sungai, Revitalisasi.

\section{PENDAHULUAN}

$\mathrm{R}$ EVITALISASI merupakan upaya untuk mengembalikan vitalitas suatu kawasan atau bagian kota yang dulunya pernah vital, namun mengalami penurunan vitalitas baik secara fisik, ekonomi, sosial dan budaya [1]. Dalam proses pendekatannya, revitalisasi harus mampu mengenali dan memanfaatkan potensi lingkungan fisik maupun non-fisik yaitu sejarah, makna, keunikan lokasi, dan citra tempat. Maka, revitalisasi tidak hanya berorientasi pada keindahan fisik tetapi juga harus mampu meningkatkan stabilitas lingkungan, pertumbuhan perekonomian masyarakat, pelestarian, dan pengenalan budaya suatu kawasan [2]

Dalam dokumen Rencana Penataan dan Revitalisasi Sungai Kalimas tahun 2006, menurut sejarahnya, perkembangan Kota Surabaya berawal dari bagian utara kota karena bagian utara merupakan bagian hulu sungai sehingga bagian utara ini akan dikenang sebagai inti sejarah kota. Keberadaan Sungai
Kalimas sangat penting bagi Kota Surabaya karena pada saat itu transportasi kota masih mengandalkan tranportasi air sehingga Sungai Kalimas sangat berperan pembangunan kota dimana pertumbuhan kota dan pusat kegiatan terkonsentrasi di sekitar Kawasan Sungai Kalimas. [3]

Namun, seiring perkembangan Kota Surabaya yang semakin pesat, kawasan sekitar Sungai Kalimas mulai menunjukkan kondisi produktivitas yang menurun karena diakibatkan oleh menurunnya nilai properti, kondisi fasilitas dan infrastruktur yang kurang memadai, dan juga kondisi wilayah serta sosial dan ekonomi yang tidak terintegrasi dengan kawasan lainnya [4] Maka, Pemerintah Kota Surabaya berencana untuk melakukan revitalisasi dengan tujuan untuk meningkatkan kembali vitalitas pada kawasan sekitar Sungai Kalimas.

Dalam rencananya, dokumen Rencana Penataan dan Revitalisasi Sungai Kalimas tahun 2006, Pemerintah Kota Surabaya membagi menjadi 9 titik revitalisasi di sepanjang kawasan Sungai Kalimas. Namun, sejak tahun 2010, Pemerintah Kota Surabaya memfokuskan revitalisasi pada kawasan Surabaya Utara yaitu Kawasan Pelabuhan Kalimas, Kawasan Jembatan Petekan, dan Kawasan Jembatan Merah. Ketiga kawasan di bagian utara ini tentu memiliki karakteristik yang berbeda dengan kawasan yang berada pada bagian tengah kota Surabaya. Sehingga, untuk melakukan revitalisasi yang sesuai dengan kondisi ketiga kawasan ini dibutuhkan identifikasi terkait potensi dan masalah pada masing-masing lokasi revitalisasi di kawasan Surabaya Utara.

\section{METODE PENELITIAN}

Variabel penelitian adalah suatu kumpulan atribut atau sifat atau nilai dari suatu obyek atau kegiatan yang ditetapkan oleh peneliti untuk dideskripsikan dan kemudian ditarik kesimpulannya. Variabel penelitian diperoleh berdasarkan kajian pustaka dan kemudian dipilih berdasarkan kesesuaiannya dengan kebutuhan penelitian. variabel yang digunakan dalam penelitian ini yaitu:

Tabel 1.

Variabel Penelitian

\begin{tabular}{ll}
\hline \hline \multicolumn{1}{c}{ Variabel } & \multicolumn{1}{c}{ Sub variabel } \\
\hline Penggunaan lahan & Lahan liar/tidak terawat \\
Letak strategis & Dekat dengan pusat kegiatan \\
Aktivitas & Bentuk kegiatan \\
Peninggalan bersejarah & Bangunan \\
\hline \hline
\end{tabular}




\begin{tabular}{ll}
\hline \hline & Tradisi kebudayaan \\
Kependudukan & Jumlah pendudukan \\
Aktivitas ekonomi & Kepadatan penduduk \\
Kondisi jaringan air & Variasi aktivitas ekonomi \\
Kondisi jaringan listrik & Ketersediaan \\
Kondisi jaringan persampahan & Ketersediaan \\
\hline \hline
\end{tabular}

Teknik pengumpulan data yang digunakan dalam penelitian ini yaitu pengumpulan data primer yang dilakukan dengan survey primer melalui wawancara mendalam ke pada stakeholder yang telah ditentukan. Kemudian, pengumpulan data sekunder yang dilakukan dengan survey sekunder melalui survey instansional dan studi literatur. Survey sekunder ini dilakukan untuk memperoleh data kependudukan, infrastruktur, serta kondisi eksisting kawasan penelitian berdasarkan dokumen-dokumen perencanaan.

Analisis yang digunakan untuk mengidentifikasi potensi dan masalah sesuai dengan variabel yang telah ditentukan yaitu Content Analysis. Content Analysis merupakan metode penelitian kualitatif yang digunakan untuk menentukan konsep-konsep yang terdapat di dalam teks hasil perekaman data.

Dari variabel yang telah ditentukan kemudian peneliti melakukan wawancara kepada kelompok stakeholder yaitu pemerintah, swasta, dan akademisi. Untuk mengidentifikasi potensi dan masalah kawasan dilakukan pengkodean yang telah ditetapkan sebelumnya. Berikut ini merupakan keterangan dari kode-kode yang ditetapkan dalam penelitian:

- G1 (Pemerintah 1: Kasub. Bidang Fisik dan Prasarana Wilayah, Bappeko Surabaya): Myrna Augusta A.D.

- G2 (Pemerintah 2: Staf Bidang Kebudayaan Dinas Kebudayaan dan Pariwisata Kota Surabaya): Widji Totok

- P1 (Swasta 1: Asisten Manager Sub-divisi Pemeliharaan Fasilitas dan Bangunan PT Pelindo III cabang Tanjung Perak): Michael

- C1 (Akademisi 1: Dosen Arsitektur ITS): Yayas

\begin{tabular}{|c|c|c|c|}
\hline \multirow{2}{*}{\begin{tabular}{|l} 
Stake \\
Holders
\end{tabular}} & \multicolumn{3}{|c|}{ Pemahaman Data Transkrip } \\
\hline & $\begin{array}{c}\text { Transkrip } \\
\end{array}$ & Kode & \multirow{3}{*}{$\begin{array}{l}\text { Analisis } \\
\text { Berdasarkan pendapat stakeholder jika } \\
\text { dilihat dari letaknya jembatan merah } \\
\text { memiliki potensi karena menjadi salah satu } \\
\text { titik transit angkutan massal berupa Trem } \\
\text { yang masih direncanakan. }\end{array}$} \\
\hline \multirow{4}{*}{ G1 } & $\begin{array}{l}\text { Salah satu titik pemberhentiannya itu } \\
\text { di Jembatan Merah. }\end{array}$ & M2.1 & \\
\hline & $\begin{array}{l}\text { Nah jembatan merahini potensial karena } \\
\text { itu adalah titik transit, salah satu titik } \\
\text { transit menuju koridor tremnya salah } \\
\text { satu titik terakhimya disitu di tahap } \\
\text { pertama }\end{array}$ & M2.2 & \\
\hline & $\begin{array}{l}\text { Karena memang potensinya dia itu dekat } \\
\text { dengan pelabuhan di utara dan dekat } \\
\text { dengan kawasan grosir }\end{array}$ & M2.3 & \multirow{2}{*}{$\begin{array}{l}\text { Berdasarakan pendapat stakeholder, } \\
\text { Jembatan Merah juga dekat dengan } \\
\text { pelabuhan di utara yang memiliki nilai } \\
\text { historis serta dekat dengan kawasan grosir } \\
\text { yang melayani tingkat regional seperti } \\
\text { JMP. Selain adanya pusat grosir, Jembatan } \\
\text { Merah memiliki lokasi yang dekat dengan } \\
\text { kawasan Wisata Religi Ampel. } \\
\end{array}$} \\
\hline & $\begin{array}{l}\text { Ada JMP kemudian ada pasar Ampel, } \\
\text { ada PGS juga }\end{array}$ & M2.4 & \\
\hline
\end{tabular}

Gambar 1. Content Analysis yang dilakukan.

Untuk huruf dan angka setelah tanda titik pertama menunjukkan variabel 1 pada dialog 1 .

Contoh: G1.M2.1

Artinya: pemerintah 1 pada variabel 1 dialog ke 1 .

\section{HASIL DAN DISKUSI}

Berdasarkan hasil pengkodean dari transkrip wawancara, potensi dan masalah pada masing-masing titik revitalisasi yaitu sebagai berikut.

\section{A. Kawasan Pelabuhan Kalimas}

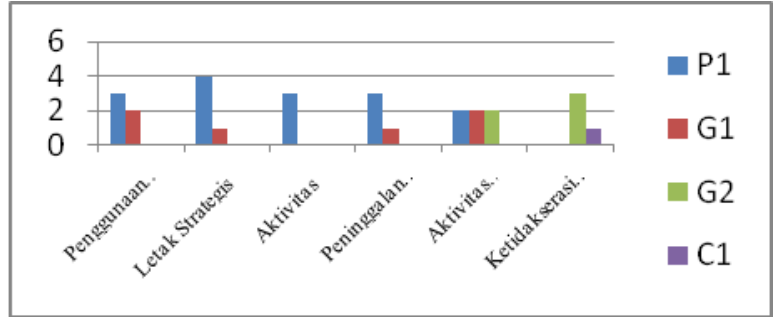

Gambar 2. Hasil analisis titik revitalisasi kawasan Pelabuhan Kalimas

Berdasarkan gambar grafik diatas, variabel peninggalan bersejarah pada kawasan Pelabuhan Kalimas serta letak strategis memiliki frekuensi yang sering disebutkan oleh stakeholder. Kawasan ini memiliki letak strategis terhadap fasilitas kegiatan pariwisata, khususnya fasilitas wisata sejarah. seperti yang terlihat pada gambar di bawah ini.

Monumen Jalesveva Jayamahe (Poin 1 dalam gambar 4.8) yang berada di kawasan Pangkalan Angkatan Laut Armada Timur. Selain itu, dekat dengan Jembatan Petekan yang memiliki nilai historis

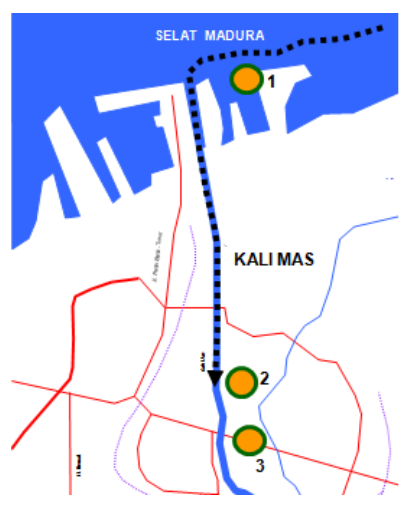

Gambar 3. Lokasi pariwisata di dekat Kalimas

\section{B. Kawasan Jembatan Petekan}

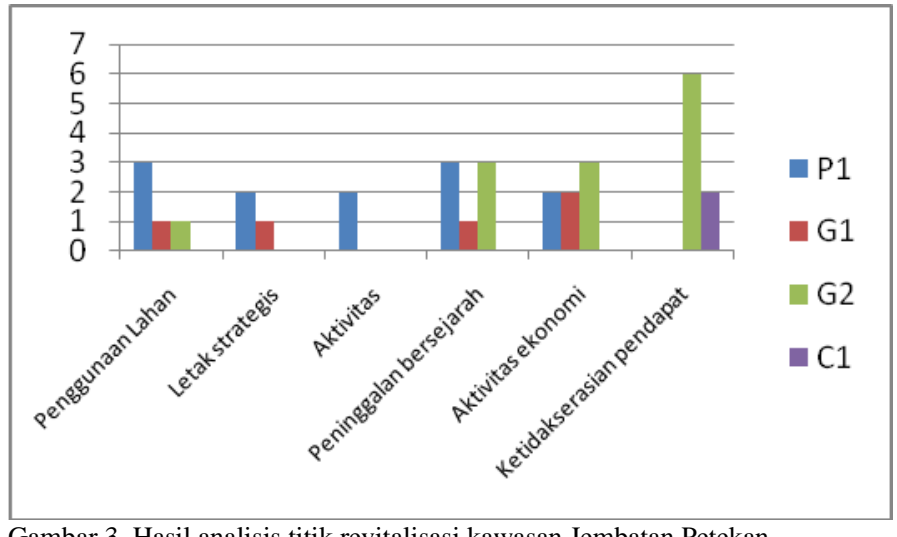

Gambar 3. Hasil analisis titik revitalisasi kawasan Jembatan Petekan

Berdasarkan gambar grafik diatas, potensi pada kawasan Jembatan Petekan adalah peninggalan bersejarah. Hal ini di dukung dengan letak strategis. Letak Jembatan Petekan yang dekat dengan Pelabuhan Kalimas yang memiliki nilai historis, selain itu juga dekat dengan Monumen Jalesveva Jayamahe (poin 1 pada Gambar 4).

Masalah pada kawasan Jembatan Petekan adalah ketidaksesuain pendapat antara pemerintah daerah dengan pemrintah kota terkait dengaan status kepemilikan Jembatan Petekan yang ditetapkan sebagai cagar budaya. 


\section{Kawasan Jembatan Merah}

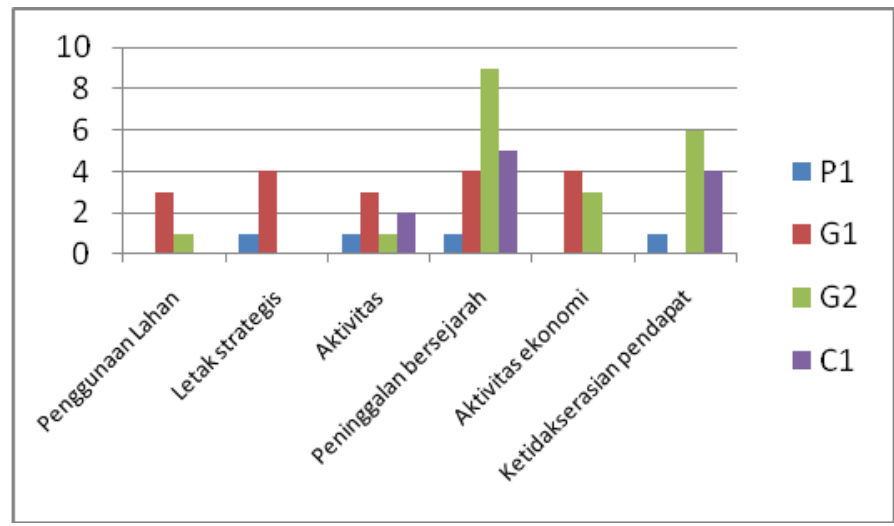

Gambar 4. Hasil analisis titik revitalisasi kawasan Jembatan Merah.

Berdasarkan grafik diatas, potensi pada kawasan jembatan merah adalah peninggalan bersejarah. Kawasan Jembatan Merah yang merupakan kawasan kota lama memiliki potensi pada perkampungan etnis yang masih bertahan hinnga sekarang yaitu perkampungan Cina yang biasa disebut Pecinan dan perkampungan Arab yang berada di kawasan Ampel. Selain itu, pada kawasan Jembatan Merah banyak terdapat bangunan-bangunan lama yang masih bertahan sejak zaman Belanda dengan kondisi yang tergolong baik karena selama ini Dinas Pariwisata masih melakukan perawatan dan pemeliharaan bangunan dengan cara pengecatan secara berkala.

Masalah pada kawasan Jembatan Merah adalah adanya ketidaksesuaian pendapat antara masyarakat dengan pemerintah kota terkait penetapan bangunan cagar budaya. Masyarakat merasa hal ini ditentukan sepihak oleh pihak pemerintah kota.

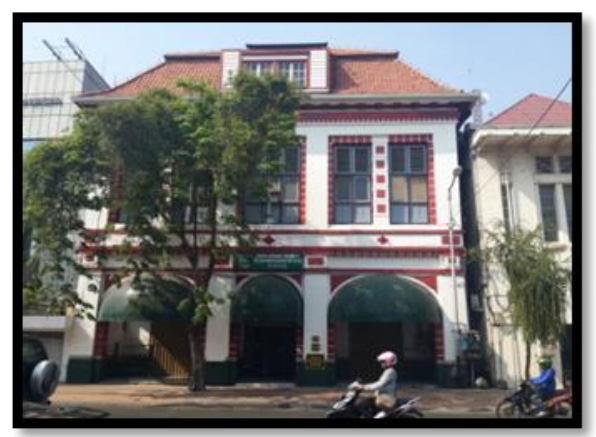

Gambar 5. Salah satu bangunan cagar budaya pada Kawasan Jembatan Merah.

\section{KESIMPULAN}

Berdasarkan hasil analisis dan pembahasan yang telah dilakukan dalam penelitian, maka dapat disimpulkan bahwa potensi dan masalah pada 3 titik revitalisasi yaitu pada ketiga titik revitalisasi memiliki potensi di bidang pariwisata terutama wisata sejarah karena banyak ditemukan bangunan cagar budaya yang memiliki nilai historis tinggi. Selain itu, dekat dengan fasilitas pariwisata lainnya serta pusat perbelanjaan. Kemudian, permasalahan pada 3 titik revitalisasi yaitu adanya ketidaksesuaian pendapat antara masyarakat dengan pemerintah, dan antara pemerintah kota dan pemerintah provinsi terkait penetapan status cagar budaya pada suatu bangunan sehingga menghambat proses pelaksanaan revitalisasi.

\section{DAFTAR PUSTAKA}

[1] Badan Perencanaan dan Pembangunan Kota Surabaya, Rencana Penataan dan Revitalisasi Sungai Kalimas. Surabaya: Pemerintah Surabaya, 2006.

[2] R. M. Ichwan, "Penataan dan Revitalisasi Sebagai Upaya Meningkatkan Daya Dukung Kawasan Perkotaan,” 2004.

[3] W. Martokusumo, "Revitalisasi, Sebuah Pendekatan Dalam Peremajaan Kawasan,” J. Perenc. Wil. dan Kota, pp. 57-73, 2008.

[4] H. Idajati, "Cultural and Tourism Planning as Tool for City Revitalization The Case Study of alimas River," Proceedia, pp. 136$141,2014$. 